\title{
THE ROLE OF MAKERSPACES IN INCLUSIVITY IN ENGINEERING
}

\author{
Justine Boudreau and Hanan Anis \\ University of Ottawa \\ jboud030@uottawa.ca, hanis@uottawa.ca
}

\begin{abstract}
The University of Ottawa Faculty of Engineering is home to multiple rapid prototyping facilities and entrepreneurship spaces. These include a makerspace, a machine shop and a design space for any student to use free of charge. First- and second-year students also take courses in the Makerlab, a sister facility to the Makerspace, which introduces them to collaborative project-based learning, engineering problem-solving and prototyping in a cornerstone design course. Maker communities and makerspaces are known to be inclusive, welcoming and low-risk, high-reward environments. The objective of this paper is twofold: the first is to understand how strongly engineering students feel included in the making and engineering communities how those feelings vary as a function of different factors, and the second is to see if intervention through engineering design improves inclusivity. This analysis was done with Kruskal-Wallis tests. Factors considered were gender, year of study, program of study and country of origin. A baseline test was done at the beginning of the semester with the students using two different perceived group inclusion tools. A second test was then done at the end of the semester to determine if feelings of inclusion had changed.
\end{abstract}

Keywords: Makerspaces, Inclusivity, Project Based Learning, Engineering Education.

\section{INTRODUCTION}

The problem identified here is that the level of inclusion in engineering university settings is not widely researched. The objectives of this paper include the study of particular demographic factors (gender, program of study, year of study, country of origin) on student perception and behavior with regards to inclusion in the University of Ottawa Faculty of Engineering and in the maker community. Many organizations and communities seek to understand their level of inclusion and ways to increase it [1]. This paper examines the effect of two cornerstone engineering design courses offered at the University of Ottawa on students' feelings of inclusion.

There is a makerspace within the University's Faculty of Engineering called the uOttawa Richard L'Abbé Makerspace, as well as an adjoining Makerlab. The Makerspace is a space open to students and the outside community where they use the equipment for free for personal or school projects, or simply to interact with the community of makers. The Makerlab is where the labs of the first- and second-year engineering design courses are run. These students learn to use the Makerspace's technology to work on their projects over the semester in a project-based learning environment based on client needs.

Makerspaces have been defined in various ways and can include assorted characteristics and features. The terminology also varies for similar types of spaces that essentially have the same function, including co-working spaces, innovation labs, media labs, fablabs, hacklabs and hackerspaces [2], [3]. In many cases, a makerspace is described as a space for digital fabrication that allows people to develop creativity, innovation, problem-solving and technical skills by working on self-selected projects [2]-[5]. Makerspaces offer training and access to shared tools, usually for a small fee [3], [6], [7]. An important characteristic is also the community of learning and collaboration that accompanies the spaces, which is a core value of the maker culture [4], [6]-[8]. They are generally informal spaces that can be located in a community setting or educational institution [3], [7]. In addition, these spaces attract people who are passionate about making and identify with the maker culture [6], [8]. They are ideally suited to an engineering educational setting, given that "engineering practice is not simply a problem solving process and specialized knowledge. It is the complex, thoughtful and intentional integration of these towards some meaningful end" [9, p. 435]. 
This study aims to identify a baseline inclusion level in the student population and ways inclusion can be increased through makerspaces and design courses. Feelings of inclusion could then be increased via the greater number of makerspaces that are popping up in universities and the greater number of people who are attending them [6].

This study aims to answer the following questions:

What are the baseline inclusion level trends for engineering design students within the making community and the Faculty of Engineering?

What is the influence of the uOttawa Makerspace on feelings of inclusion for engineering design students within the making community and the Faculty of Engineering?

\section{BACKGROUND}

\subsection{Maker Movement and Inclusion}

Makerspaces provide a lot of value for their members and their surrounding community [3]. They permit people to fail in a safe environment where they have the creative freedom to try again and seek expert help when needed [10], [11]. The maker culture embedded within the spaces and their members includes characteristics of "making" (building, modifying and designing) and of "makers" (problem-solving, discovering, collaborating and learning) [8]. This culture defines makerspaces as more than simply collections of tools by creating a community of learning and shared space that promotes principles like inquiry, play, innovation, critical thinking and personalized learning [3], [10]. Hands-on learning is also facilitated, which helps makerspace users build confidence while developing interdisciplinary thinking and teamwork skills [5], [12]. In addition to makerspaces, maker culture and the maker movement, maker identity represents the typical characteristics of the people who integrate themselves in the maker culture. The maker movement is characterized by a maker mindset that comprises values, beliefs and dispositions common to the community — in other words, the maker mindset is indicative of the maker identity [8].

The maker movement is based heavily on experiential learning, or "learning by doing" [13]. It is "a growing movement of hobbyists, tinkerers, engineers, hackers, and artists committed to creatively designing and building material objects for both playful and useful ends" [8, p.
30]. Makerspaces facilitate hands-on learning and the incorporation of project-based learning into the curriculum of engineering education in universities and in STEM education in K-12 (primary and secondary school) [11], [13]. They integrate well into the engineering design mindset, something that has led to successful implementations of makerspaces within the university community, as Talley et al. [13, p. 2] state: "A close relationship exists between the engineering design process and making." They explain how makerspaces are relevant to engineering education based on the following factors: learning is an active and constructive process, construction of knowledge happens well through the building and sharing of objects, education should be experiential and connected to real-world situations, and design is an engineering pedagogical method that is accessible to many types of learners [13]. These ideas are seconded by Martin [8], who highlights three aspects of the maker movement that are beneficial to engineering education: digital tools encourage easy making; community infrastructure provides for member engagement, sharing and collaborative problem-solving; and the maker mindset describes participation as playful, asset- and growth-oriented, failure-positive and collaborative. Saorin et al. [2] also support makerspace implementation in education because it serves to bridge gaps between science, technology and arts and promotes the increase of creativity in interdisciplinary settings.

Engineering education has the goal of graduating people who have the skills industry is looking for, who can define and solve a problem, who can design and who have complex design thinking skills [2], [14]. Creativity, invention and innovation have also been identified as indispensable qualities for engineering [13]. Before 1990, engineering graduates were often perceived by both industry and academia as incapable of making the jump from theoretical to practical once in the workforce due to their lack of practice with the design process [14]. Finalyear capstone design courses and a later addition of firstyear cornerstone design courses were integrated to respond to this problem [14]. These courses typically use project-based learning to teach students design and include a real-life hands-on problem to be solved by a team of students, providing them with experiential learning that helps increase their creativity and design thinking [14].

Given that the community of learning and collaboration is a core value of maker culture, inclusivity 
would also appear to be a characteristic of makerspaces. Inclusivity, "seen as the satisfaction of individual needs within a group[,] consists of belongingness and uniqueness [and] it is the group that includes the individual" [1, p. 370]. The elements of group inclusion that consist of perceptions of belonging and authenticity [1] are naturally present in a maker community as described here. Maker projects have the ability to empower makers through social projects, such as the creation of assistive technologies, for example [3]. Projects that include culturally meaningful curriculum or relate to meaningful personal or community problems are empowering [13]. Taking part in the maker movement opens up participants to an inclusive community of collaborators and like-minded people [15].

\subsection{Courses}

To address the need for cornerstone design courses in engineering curriculum and to take advantage of the clear link with the maker movement, uOttawa developed its first- and second-year engineering design courses around principles of project-based learning. The first-year engineering design course, called Engineering Design, is mandatory for first-year mechanical, biomedical mechanical, electrical and civil engineering students. The second-year engineering design course, Introduction to Product Development and Management for Engineers and Computer Scientists, is open to all departments of engineering and to computer scientists from different years. The focus of both courses is on client-centred design, where groups of students work on a specific client's problem or needs during one semester and deliver a final physical prototype. Groups are formed from multidisciplinary and multi-year engineering and computer science students within the first two weeks of class. The first assignment for the first week of class is a personality assessment, and with that information, the students are typically instructed to find diverse team members to complement themselves in terms of personality and program, to form groups of four to six members.

The two main components of the course are the lectures and the labs. In the lectures, the students learn design methodologies, processes for product development, and time and project management. Students in the second-year course also learn about business models, economics and marketing. Students then put these skills to use in their own semester-long project. Their iterative conceptual and prototyping work is done mostly at home, with some lab time dedicated to working on the project. The rest of the labs are designed to teach students the skills necessary to be able to do their projects or to give them enough of an introduction that they can learn more by themselves if needed.

The theme for the first-year course changes almost every semester and is different between sections. The theme for the second-year course is accessibility, so students work on projects like wheelchair skis, portable wheelchair ramps or foot-controlled guitars. Clients are diverse, ranging from individuals to organizations like hospitals, and all have different needs.

Both courses have one teaching assistant (TA), who is a graduate student, and a project manager (PM), who is a senior student who has taken the course previously. They act as guides and mentors to the groups as they go through their design process and learn the skills necessary to complete their projects.

Some people already feel included in this environment; however, others may feel more included after taking the course, while others never feel included.

\subsection{Methods}

The research paradigm for this study is interpretive research to understand how people see and interpret their experiences in makerspaces and to build theory as the study progresses. It is important to put ourselves in the shoes of the users to better comprehend what factors may affect them with regards to inclusion. An inductive method was used so that no prejudices would influence the research data in this exploratory study.

A quantitative approach was implemented through an online survey. The students in the engineering design courses were the primary sample.

The students were surveyed about their feelings of inclusion as makers and as engineers. Two different inclusion surveys were used to be able to validate the results: the perceived group inclusion scale [1] and the psychological need-satisfaction scale [16], both of which can be found in Appendix A. The surveys were used to understand levels of inclusion within engineering and making. They collected quantitative data from a 5- to 7point Likert scale, to measure inclusion within the specific groups of "maker" and "engineer," as well as personal identifiers including year of study, program of study, 
gender and country of origin. Both surveys looked at perceptions of authenticity and belonging within a group. The definition of the groups "maker" and "engineer" that were provided to the students can be found in Appendix B. The surveys were administered in the first few weeks of the semester and again in the last week to all cornerstone engineering design course students (approximately 400 total). A comparison of means was done with the survey results between perception of inclusion, origin and the other factors.

\section{RESULTS AND DISCUSSION}

Since the uOttawa Makerspace was launched in September 2014, it has expanded twice and is now in a space more than triple in size. In addition, the engineering design courses that started with eight students in 2016 included nearly 1,000 by the 2018-2019 academic year. Since there is so much expansion and more people than ever will be exposed to the Makerspace and these courses, there is value in studying and understanding their effect on the feelings of inclusion within the Faculty of Engineering and within the maker community. It is also important to understand how student experience and retention could be improved, given that the feeling of being included in the engineering community (or of forming an engineering identity) is crucial to students committing to engineering during and after graduation [17].

Results were collected in the fall 2018 and winter 2019 terms as part of the normal operation of the courses. The following sections describe the steps taken to answer the question "What is the influence of the uOttawa Makerspace on the inclusion of engineering design students within making and the Faculty of Engineering?" First, a baseline of the pre-course results is outlined. Second, the two survey tools are compared. And finally, the pre- and post-course inclusion score differences are analyzed.

\subsection{Baseline Inclusion Scores}

To determine if the baseline making and engineering scores were related, a Spearman's Rho correlation was run. There was a statistically significant, strong positive correlation between both groups, $\mathrm{r}_{\mathrm{s}}(183)=.802, \mathrm{p}<.05$, leading us to conclude that most students had the same feelings of inclusion in both the maker community and the engineering community and may not even differentiate them.

The following sections explore the variation in inclusion scores by gender, program, year and country of origin for the maker community and the engineering community before taking the design course.

\subsubsection{Gender}

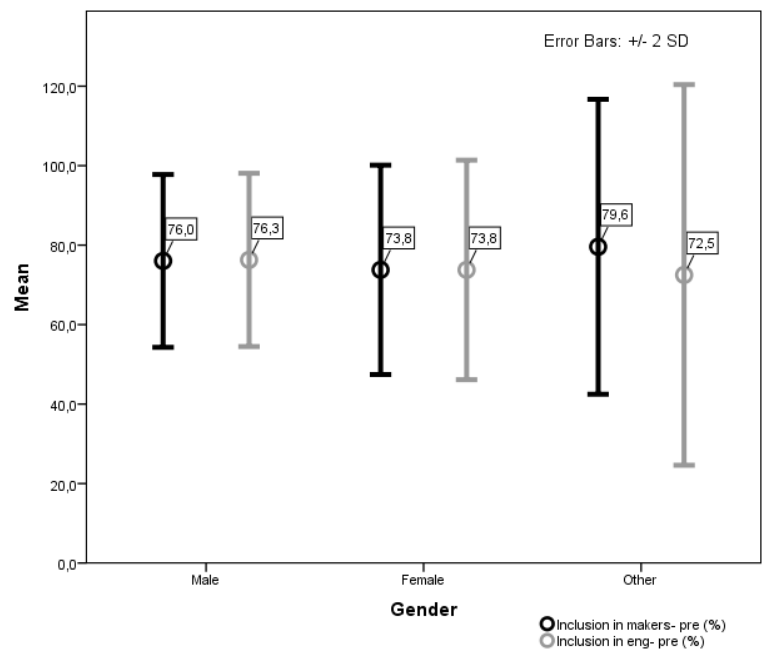

Figure 1 Baseline inclusion: gender

For each gender, there was again no difference between making and engineering. However, there was a larger variation in scores and a lower mean for females than for males, as shown in Table 1. This leads to the conclusion that females would feel less included in both groups. The maker and engineer differences in gender were, however, shown to not be significant based on Kruskal-Wallis tests, $\chi^{2}(2)=1.188, \mathrm{p}=.552$ and $\chi^{2}(2)=$ $1.857, \mathrm{p}=.395$ respectively.

Table 1 Gender descriptives

\begin{tabular}{|l|l|l|l|l|l|}
\hline Gender & $\mathbf{N}$ & $\begin{array}{l}\text { Mean: } \\
\text { Maker }\end{array}$ & $\begin{array}{l}\text { Std. } \\
\text { Dev.: } \\
\text { Maker }\end{array}$ & $\begin{array}{l}\text { Mean: } \\
\text { Eng. }\end{array}$ & $\begin{array}{l}\text { Std. } \\
\text { Dev.: } \\
\text { Eng. }\end{array}$ \\
\hline Male & 142 & 76.03 & 10.87 & 76.29 & 10.91 \\
\hline Female & 46 & 73.77 & 13.18 & 73.78 & 13.81 \\
\hline Other & 3 & 79.58 & 18.55 & 72.50 & 23.95 \\
\hline
\end{tabular}




\subsubsection{Program of study}

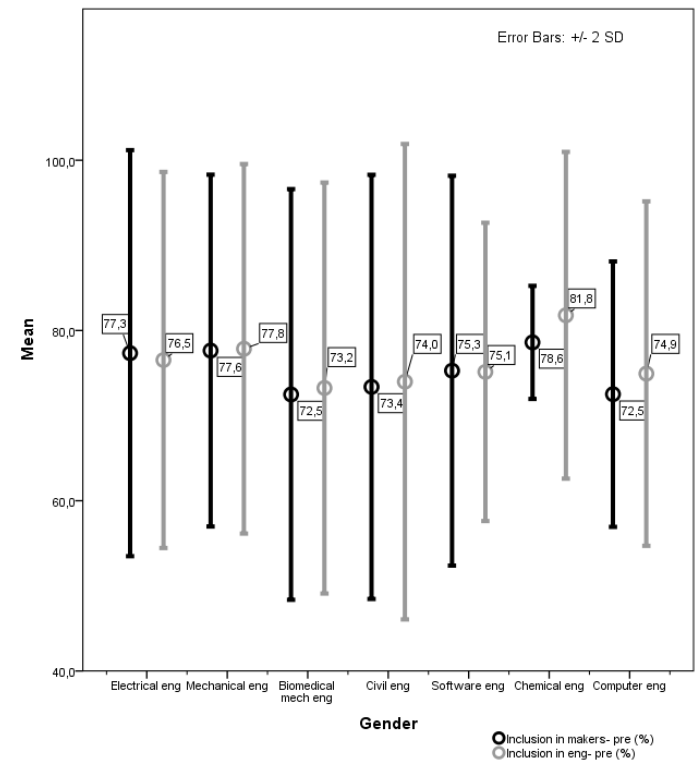

Figure 2 Baseline inclusion: maker vs program of study

The program of study showed some difference in inclusion scores for both making and engineering; however, the means were all around $75 \%$, with the standard deviations showing values between $55 \%$ and $100 \%$. A Kruskal-Wallis test was conducted to determine if there were significant differences in the average baseline inclusion scores for both communities for program of study. The maker and engineer differences were shown to not be significant, $\chi^{2}(7)=6.205, \mathrm{p}=.516$ and $\chi^{2}(7)=5.451, \mathrm{p}=.605$ respectively. We also noticed the same mean and standard deviation distribution of scores between feelings of inclusion in making and in engineering, with the exception of chemical and computer engineering. There is a larger variation for chemical engineering because there were only two students in this sample. However, students in computer engineering seem to feel less like makers than engineers, with a tighter grouping at a lower mean. The descriptives of each program are shown in Table 2. We can also observe that biomedical mechanical and civil engineering have lower means than the other programs. Biomedical mechanical engineering has $43 \%$ females in this sample, something that can lead to a lower mean as discussed in the previous section. However, civil engineering has only $21 \%$ females, and its mean was only slightly higher than that of biomedical mechanical engineering. The relationship between programs should be studied further to understand what other effects could influence the inclusion scores.
Table 2 Program of study descriptives

\begin{tabular}{|l|l|l|l|l|l|}
\hline $\begin{array}{l}\text { Eng. } \\
\text { Program }\end{array}$ & $\mathbf{N}$ & $\begin{array}{l}\text { Mean: } \\
\text { Maker }\end{array}$ & $\begin{array}{l}\text { Std. } \\
\text { Dev.: } \\
\text { Maker }\end{array}$ & $\begin{array}{l}\text { Mean: } \\
\text { Eng. }\end{array}$ & $\begin{array}{l}\text { Std. } \\
\text { Dev.: } \\
\text { Eng. }\end{array}$ \\
\hline Electrical & 43 & 77.33 & 11.93 & 76.53 & 11.05 \\
\hline Mechanical & 58 & 77.64 & 10.33 & 77.85 & 10.85 \\
\hline $\begin{array}{l}\text { Biomedical } \\
\text { mechanical }\end{array}$ & 21 & 72.48 & 12.06 & 73.24 & 12.07 \\
\hline Civil & 44 & 73.38 & 12.46 & 73.99 & 13.96 \\
\hline Software & 9 & 75.28 & 11.45 & 75.14 & 8.76 \\
\hline Chemical & 2 & 78.60 & 3.33 & 81.79 & 9.60 \\
\hline Computer & 7 & 72.52 & 7.79 & 74.93 & 10.12 \\
\hline
\end{tabular}

\subsubsection{Year of Study}

The year of study showed similar results. All years seemed to have the same inclusion scores for making and engineering. Table 3 shows this with the descriptives for year of study. In making, we expected similar results in different years; however, in engineering we expected there to be greater variation, with students in fourth year feeling more included in engineering. We may not be seeing this here because the numbers of students in third and fourth year in the sample are low. The Kruskal-Wallis test was conducted to determine if there were significant differences in the average baseline inclusion scores for both communities for year of study. The maker and engineer differences in year of study were not shown to be significant, $\chi^{2}(3)=.538, p=.910$ and $\chi^{2}(3)=.959, p=$ .811 respectively.

Table 3 Year of study descriptives

\begin{tabular}{|l|l|l|l|l|l|}
\hline Year & N & $\begin{array}{l}\text { Mean: } \\
\text { Maker }\end{array}$ & $\begin{array}{l}\text { Std. } \\
\text { Dev.: } \\
\text { Maker }\end{array}$ & $\begin{array}{l}\text { Mean: } \\
\text { Eng. }\end{array}$ & $\begin{array}{l}\text { Std. } \\
\text { Dev.: } \\
\text { Eng. }\end{array}$ \\
\hline 1st & 112 & 75.48 & 11.29 & 76.00 & 11.45 \\
\hline 2nd & 58 & 75.15 & 12.36 & 74.64 & 13.15 \\
\hline 3rd & 9 & 78.71 & 8.21 & 76.53 & 9.96 \\
\hline 4th & 12 & 75.59 & 13.21 & 76.26 & 11.52 \\
\hline
\end{tabular}




\subsubsection{Country of Origin}

The origin variable was constructed based on the respondents' country of origin answer: Canada is local, and everything else is international. The country of origin of the students was not shown to make a difference in their inclusion scores in making or engineering, with Kruskal-Wallis tests $\left(\chi^{2}(1)=.519, \mathrm{p}=.471\right.$ and $\chi^{2}(1)=$ $.016, \mathrm{p}=.898$ respectively). The relationships can also be seen in Table 4.

Table 4 Origin descriptives

\begin{tabular}{|l|l|l|l|l|l|}
\hline Origin & N & $\begin{array}{l}\text { Mean: } \\
\text { Maker }\end{array}$ & $\begin{array}{l}\text { Std. } \\
\text { Dev.: } \\
\text { Maker }\end{array}$ & $\begin{array}{l}\text { Mean: } \\
\text { Eng. }\end{array}$ & $\begin{array}{l}\text { Std. } \\
\text { Dev.: } \\
\text { Eng. }\end{array}$ \\
\hline Local & 121 & 76.04 & 11.53 & 75.51 & 11.99 \\
\hline $\begin{array}{l}\text { Internati } \\
\text { onal }\end{array}$ & 70 & 74.68 & 11.65 & 75.83 & 11.73 \\
\hline
\end{tabular}

\subsection{Survey Tools}

Two different tools (the perceived group inclusion scale and the psychological need-satisfaction scale) were used to determine the validity of the results: the first was used in the fall 2018 semester, and both were used in the winter 2019 semester. A Kruskal-Wallis test was conducted to determine if there were differences in the average survey scores of baseline making, baseline engineering, delta making and delta engineering between these tools.

Table 5 Kruskal-Wallis tests on survey tools

\begin{tabular}{|l|l|l|l|l|}
\hline & $\begin{array}{l}\text { Base: } \\
\text { Maker }\end{array}$ & $\begin{array}{l}\text { Base: } \\
\text { Eng. }\end{array}$ & $\begin{array}{l}\text { Delta: } \\
\text { Maker }\end{array}$ & $\begin{array}{l}\text { Delta: } \\
\text { Eng. }\end{array}$ \\
\hline N (1st tool) & 150 & 150 & 63 & 63 \\
\hline $\begin{array}{l}\text { Mean (1st } \\
\text { tool) }\end{array}$ & 76.200 & 76.525 & 1.845 & 1.964 \\
\hline N (2nd tool) & 41 & 41 & 7 & 7 \\
\hline $\begin{array}{l}\text { Mean (2nd } \\
\text { tool) }\end{array}$ & 73.124 & 72.334 & 4.762 & 6.803 \\
\hline$\chi^{\mathbf{2}(1)}$ & 1.882 & 3.824 & 0.230 & 2.250 \\
\hline $\mathbf{p}$ & 0.170 & 0.051 & 0.631 & 0.134 \\
\hline
\end{tabular}

None of the tests were significant ( $p>0.05)$, indicating the means between the two tools were not significantly different. Therefore, both tools are valid and can be used in this case.

\subsection{The Difference in Inclusion Scores Due to Intervention}

The delta inclusion scores were calculated based on the difference of the pre- and post-course inclusion scores at the beginning and end of the semester. For each factor, Kruskal-Wallis tests were again conducted to determine if there were significant differences in the average delta scores for both communities - making and engineering. When looking at the delta in the making and engineering inclusion scores, there was no significant difference for any of the factors as demonstrated below ( $p>0.05$ ).

Maker: gender: $\chi^{2}(2)=4.187, p=.123$

Maker: program of study: $\chi^{2}(8)=7.940, \mathrm{p}=.439$

Maker: year of study: $\chi^{2}(3)=1.828, \mathrm{p}=.609$

Maker: origin: $\chi^{2}(1)=.002, \mathrm{p}=.965$

Eng.: gender: $\chi^{2}(2)=1.750, p=.417$

Eng.: program of study: $\chi^{2}(8)=5.347, \mathrm{p}=.720$

Eng.: year of study: $\chi^{2}(3)=1.177, \mathrm{p}=.759$

Eng.: origin: $\chi^{2}(1)=.087, p=.769$

The reason there was no significant difference here might stem from the fact that a 12 -week semester is not long enough for a feeling of inclusion to change. Further research should be done on a longer time frame to try to measure any effect. Other groups, like engineers who are not taking one of the two design courses and makers who participate in the Makerspace, should also be tested to establish a comparison for this group of students.

\section{CONCLUSION}

Anecdotally, we know that integrating makerspaces into engineering design helps students feel more included and more like engineers. The survey results were meant to collect a baseline inclusion score for students in the uOttawa cornerstone engineering design courses. They were also used to indicate whether students felt more or less included in engineering and in making after taking a hands-on project-based learning course centered on client interaction and making principles. The inclusion scores for making and engineering were not significant for any of the gender, program of study, year of study or country 
of origin factors. On the other hand, some interesting baseline results revealed that females seem to have lower scores, program of study has a variation in scores that needs to be studied further, and the students' year of study should not give constant results. We also hypothesize that three months is not long enough to see a change in feelings of inclusion where there are no significant relationships with the differences. Therefore, more work needs to be done on inclusion in engineering design courses to understand the feelings of inclusion and the effects they have on students' performance.

\section{Acknowledgements}

These programs are possible thanks to the NSERC Chair in Entrepreneurial Engineering Design.

\section{References}

[1] W. S. Jansen, S. Otten, K. I. Van Der Zee, and L. Jans, "Inclusion: Conceptualization and measurement," Eur. J. Soc. Psychol., vol. 44, pp. 370-385, 2014.

[2] J. L. Saorín, D. Melian-Díaz, A. Bonnet, C. Carbonell Carrera, C. Meier, and J. De La Torre-Cantero, "Makerspace teaching-learning environment to enhance creative competence in engineering students," Think. Ski. Creat., vol. 23, pp. 188-198, 2017.

[3] N. Taylor, U. Hurley, and P. Connolly, "Making community: the wider role of makerspaces in public life," in CHI '16: Proceedings of the 2016 CHI Conference on Human Factors in Computing Systems, 2016, pp. 14151425.

[4] D. Davis and L. L. Mason, "A behavioral phenomenological inquiry of maker identity.," Behav. Anal. Res. Pract., vol. 17, no. 2, pp. 174-196, 2017.

[5] S. Whitmer, "Makerspaces That Set the Stage for Lifelong Learning," in Open Conference, 2016.

[6] S. Farritor, "University-Based Makerspaces: A Source of Innovation," Technol. Innov., vol. 19, no. 1, pp. 389-395, 2017.

[7] S. Y. Han, J. Yoo, H. Zo, and A. P. Ciganek, "Understanding makerspace continuance: A selfdetermination perspective," Telemat. Informatics, vol. 34, no. 4, pp. 184-195, 2017.

[8] L. Martin, "The Promise of the Maker Movement for Education," J. Pre-College Eng. Educ. Res., vol. 5, no. 1, pp. 30-39, 2015.

[9] S. Sheppard, A. Colby, K. Macatangay, and W. Sullivan, "What is Engineering Practice?," Int. J. Eng. Educ., vol. 22, no. 3, pp. 429-438, 2006.

[10] J. M. Hughes, "Digital making with 'At-Risk' youth," Int J. Inf. Learn. Technol., vol. 34, no. 2, pp. 102-113, 2017.

[11] D. Smay and C. Walker, "Makerspaces: A Creative Approach to Education," Teach. Libr., vol. 42, no. 4, pp. 39-44, 2015.

[12] C. Clauson and R. Sheth, "University-Industry
Collaborations Are Driving Creation of Next-Generation Learning Spaces," Plan. High. Educ. J., vol. 45, no. 4, pp. 105-117, 2017.

[13] S. F. Talley, Kimberly Grau; Ortiz, Araceli Martinez; Sriramen, Verdaraman; Smith, "The Engineering Education Maker Identity Project: A Look at the First Year The Engineering Education Maker Identity Project : A Look at the First Year Abstract," in American Society for Engineering Education, 2017.

[14] C. Dym, A. Agogino, O. Eris, D. Frey, and L. Leifer, "Engineering Design Thinking, Teaching, and Learning," J. Eng. Educ., vol. 34, no. 1, pp. 103-120, 2005.

[15] T. Honma, "Advancing Alternative Pathways to Science Community Partnership, Do-It-Yourself (DIY)/Do-ItTogether (DIT) Collaboration, and STEM Learning 'from Below,"” Transform. J. Incl. Scholarsh. Pedagog., vol. 27, no. 1, pp. 41-50, 2017.

[16] K. M. Sheldon and B. A. Bettencourt, "Psychological need-satisfaction and subjective well- being within social groups," Br. J. Soc. Psychol., vol. 41, pp. 25-38, 2002.

[17] R. Stevens, K. O'Connor, L. Garrison, A. Jocuns, and D. M. Amos, "Becoming an Engineer: Toward a Three Dimensional View of Engineering Learning," J. Eng. Educ., no. July, pp. 355-368, 2008.

\section{APPENDIX A}

Perceived group inclusion scale [1]

1. This group gives me the feeling that I belong.

2. This group gives me the feeling that I am part of this group.

3. This group gives me the feeling that I fit in.

4. This group treats me as an insider.

5. This group likes me.

6. This group appreciates me.

7. This group is pleased with me.

8. This group cares about me.

9. This group allows me to be authentic.

10. This group allows me to be who I am.

11. This group allows me to express my authentic self.

12. This group allows me to present myself the way I am.

13. This group encourages me to be authentic.

14. This group encourages me to be who I am.

15. This group encourages me to express my authentic self.

16. This group encourages me to present myself the way I am. 
Psychological need-satisfaction scale [16]

1. How included do you feel in this group?

2. To what extent do you feel well-integrated into this group?

3. To what extent do you feel a sense of belongingness within the group?

4. How much do you feel like you stand out within this group?

5. How much do you feel unique as you participate in the group?

6. How distinct and separate do you feel within this group?

7. How different is your group from other groups?

8. How much does this group seem to stand out, compared to other groups?

9. How much does this group seem unique, compared to other groups?

10. How free and choiceful do you feel as you participate in this group?

11. How much do you feel wholehearted (as opposed to feeling controlled or pressured) as you do things for this group?

12. To what extent does this group membership allow you to express your authentic self?

13. How close and connected do you feel with other members of the group?

14. How much of a sense of relatedness do you feel with the other members of the group?

15. To what extent do you feel a sense of personal friendship with the other group members?

\section{APPENDIX B}

Definitions of "maker" and "engineer," as provided to students in the survey:

Maker: "Activities focused on designing, building, modifying, and/or repurposing material objects, for playful or useful ends, oriented towards making a 'product' of some sort that can be used, interacted with, or demonstrated." [8, p. 31]

Engineer: "Engineering practice is not simply a problem solving process and specialized knowledge. It is the complex, thoughtful and intentional integration of these towards some meaningful end." [9, p. 435] 